\title{
A NUMERICAL STUDY FOR ANALYSING CRACKED REINFORCED CONCRETE BEAMS REPAIRED BY GLUING STEEL PLATES
}

\author{
Usama Mostafa MAHRAN \\ Lecturer of civil Engineering Department, Faculty of Engineering, Assiut \\ University, Assiut, EGYPT.
}

(Received June 11, 2006 Accepted July 10, 2006)

The basic concept of using the finite element method of analysis in constructing an analytical models for the study of behavior of reinforced concrete members is discussed. The finite elements method chosen to represent the concrete, the steel reinforcement, and the bond links between the concrete and steel reinforcement are described, modeling with a proper finite element program in idealization the considered structure is greatly needed. This paper demonstrates the behavior of reinforced concrete cracked beams. Five reinforced concrete beams with cross section width $(b=10 \mathrm{~cm})$ and thickness $(t=40 \mathrm{~cm})$, the bottom reinforcements are is $4 \phi 16 \mathrm{~mm}$ and top reinforcement (stirrups hanger) $2 \phi 10 \mathrm{~mm}$. Beams R8, C8, C6, C5 and C7, are with stirrups $\phi 6 \mathrm{~mm}$ each $10 \mathrm{~cm}$ from the span of the beam which equal $220 \mathrm{~cm}$ [ 5].

Beams C8, C6 and C5 were repaired by a steel plate $6 \mathrm{~mm}$ thickness with different length $2 d, 4 d$ and $6 d$ respectively, in tension zone glued by epoxy material, while beam C7 was repaired by two steel plates $6 \mathrm{~mm}$ thickness with lengths $6 d$, one in tension zone and the other in compression zone [ 5 ]. The load was applied in the middle span of the beams and all beams were designed as tension failures so that, the distance of point of test load from the support equal more than three times of the depth of the tensile steel. I suggest new formula in the two dimensional for numerical modeling for the plane element.

KEYWORDS: repairing; gluing, numerical modeling

\section{INTRODUCTION}

An important characteristic of concrete is its cracking behavior at low tensile stresses. The cracking of concrete is a major factor contributing to the nonlinear behavior of reinforced concrete structures. Realistic theoretical analyses taken into consideration, the cracking in concrete even under service loads. The cracking in concrete. Structures have widely been modeled in finite element analyses by adjustment the element stiffness. There are three different approaches have been employed the crack modeling. 


\section{2-Smeared Cracking Model}

In this approach, the cracked concrete is assumed to remain a continuum which means that cracks smeared out in a continuous fashion, In this models the cracks are not discrete but implies an infinite number of parallel fissures across that part of the finite element as shown in Fig. 1.

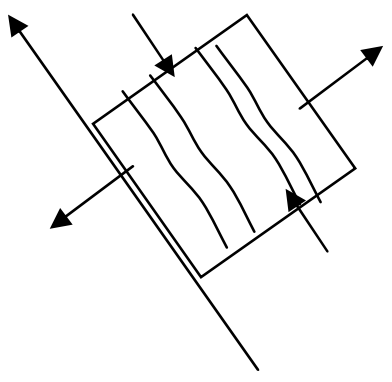

Fig. 1: Smeared Cracking Model.

\section{3- Discrete Cracking Model}

An alternative to the continuous smeared cracking model is the introduction of discrete cracks. This is normally done by disconnecting the displacement at nodal points for adjoining elements as shown in Figs. 2, 3.
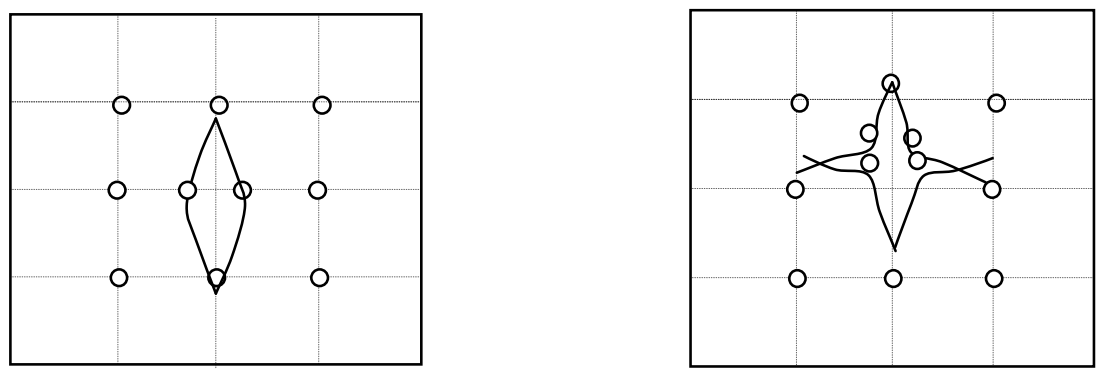

Figs. 2, 3: Discrete Cracking Model [ 6 ].

\section{Crack Modeling}

In this work, the diversion of stiffens matrix of in plane rectangular element of smeared cracked is introduced for reinforced concrete beams and slabs.

To make this diversion representing the real behavior of concrete structures, some assumptions have been assumed.

a- Since the concrete is considered as a brittle material as proved previously, the element is considered to be elastic even cracks occur. 
b- It is a usual assumption that, forming cracks is a brittle processes and the stress in tension loading direction operability goes to zero

c- When principal strain exceeded its limiting value, cracks are assumed to occur normal to the direction of these stresses.

d- The displacements shape function is assumed to have linear shape function in horizontal direction and cubic polyamine function thus to represent the actual deflection shape of reinforced concrete beams.

Simple model of the forming cracks in reinforced concrete is proposed, the cracks are formed in the direction of major principal tensile strain and that direction can change with changing in strains. The crack is formed when the major principal strain in the concrete exceeds the tensile strain. This is based on that the crack direction is taken to be perpendicular to the direction of major principal strain at any stage of loading. This implies that as the principal strain direction changes so does the crack direction which call swinging crack.

Initially, a crack is formed the principal strain direction so does the principal stress direction and this leads to a change in the stiffness, and consequently to unbalanced stresses. At this stage, there may be unbalanced shear stress applied parallel to the crack, and then the principal stress direction in concrete is then not perpendicular to the crack direction so, if the principal tensile stress exceeds its tensile capacity, new crack would be formed and the original crack is closed.

This process would continue until the principal tensile stress in concrete is no longer in excess of its tensile capacity, and equilibrium is established. If we also assume that the tensile capacity of concrete become zero after the first crack has been formed, then in equilibrium state, both the shear strain and the shear stress would be zero. This model has been proposed by (Ajaya K. Gupta and Habiballah Akbar [2]).

The element stiffness matrix $K^{e}$ is represented by the following equation

$$
K^{e}=\int_{V e} B_{m}^{T} D_{m} B_{m} \cdot d V+\int_{V r} B_{m}^{T} D_{r} B_{m} \cdot d V
$$

Where

$\mathrm{B} m=$ strain displacement matrix for the (2D) parent element

$\mathrm{D} m$ = elasticity matrix of the matrix

$V e=$ element volume

$\mathrm{D} r$ = elasticity matrix of the rebar with respect to local coordinates

In the above equation (1) it can be seen that the strain-displacement matrix $B_{m}$ of the rebar is expressed by the same Shape Function as for the matrix portion.

By using the four points Gauss numerical integration $(n=4)$ in the $r$ and s directions, the following matrix $[\mathrm{H}]$ contain the interpolation function $h i j=1, \ldots \ldots, 4$ and is defined as in equation (2).

$$
[H]=\left(\begin{array}{cccccccc}
h_{1} & 0 & h_{2} & 0 & h_{3} & 0 & h_{4} & 0 \\
0 & h_{1} & 0 & h_{2} & 0 & h_{3} & 0 & h_{4}
\end{array}\right)
$$


The strains in both domains of the element and rebar, are referenced to the local coordinate $(\mathrm{x}, \mathrm{y})$, whereas the displacements are expressed in terms of natural coordinate systems $(\mathrm{r}, \mathrm{s}$ derivatives and the $(\mathrm{x}, \mathrm{y})$ derivatives are of the form given in equation (3), [4].

$$
\partial / \partial r=J \partial / \partial x
$$

where $J$ is Jacobin operator.

The elements of strain-displacement transformation matrix $\mathrm{Bm}$ are affected by the Jacobin operator as

$$
\left[\mathrm{B}_{\mathrm{m}}\right]=\left[\mathrm{L}_{\mathrm{m}}\right][\mathrm{H}]
$$

where $\mathrm{L}_{\mathrm{m}}$ is the differential operator representing small deformation under conditions of stress given as [5]:

$$
\begin{aligned}
& {\left[L_{m}\right]=\left(\begin{array}{ll}
\partial / \partial x & 0 \\
0 & \partial / \partial y \\
\partial / \partial y & \partial / \partial x
\end{array}\right)} \\
& K^{e}=\sum_{i=1}^{G P m} B_{m, i}^{T} D_{m, i} B_{m, i} . \operatorname{det} J . \alpha_{i}+\sum_{j=1}^{n r} \sum_{i=1}^{G P r} B_{m, i}^{T} T_{\beta, i}^{T} D_{r, i} T_{\beta, i} B_{m, i} . l_{r, i} . A_{r, i}
\end{aligned}
$$

where

$G p m=$ number of Gauss points associated to the matrix portion

$d v \quad=$ volume of the element

$B m$ = strain displacement matrix for the (2D) parent element

$D m$ = elasticity matrix of the matrix of two node BAR element

$n r \quad=$ number of rebars

$l r, i \quad=$ length of the $\mathrm{i}$-th rebar

$A r, i=$ cross-sectional area of the i-th rebar

In general, the material directions will not coincide with the element reference axes, so the transformation matrix $T_{\beta, i}$

$$
\left[T_{\beta, i}\right]=\left(\begin{array}{ccc}
C^{2} & S^{2} & -2 S C^{2} \\
S^{2} & C^{2} & +2 S C \\
C S & S C & C^{2}-S^{2}
\end{array}\right)
$$

where 
$\mathrm{S}=\sin \partial$

$\mathrm{C}=\cos \partial$

where $\partial$ is the angle measured counter clockwise from the element $\mathrm{x}$-axis.

The stresses are given by equation (6)

$$
[\sigma]=[D][\in]
$$

where

$$
[D]=E_{c}\left(\begin{array}{ccc}
S^{4} & S^{2} C^{2} & -S C^{3} \\
S^{2} C^{2} & S^{4} & -S^{3} C \\
-C^{3} S & -S^{3} C & S^{2} C^{2}
\end{array}\right)
$$

and

$$
[D]^{*}=[D]+[G]
$$

In which $\mathrm{G}$ represents the effects of possible change in the crack direction

$$
[G]_{c}=\frac{0.5 \sin \theta Z^{c}}{\sqrt{\left(\in_{x}-\in\right)^{2}+\gamma_{x y}^{2}}}\left(\begin{array}{ccc}
1 & 1 & -w \\
-1 & 1 & w \\
-w & w & w^{2}
\end{array}\right)
$$

where

$\mathrm{w}=\cot 2 \theta$

$Z^{c}=\frac{\tau_{x y}}{\sin \theta \cos \theta}$

\section{COMPARISON OF THEORETICAL RESULTS}

The strains and Displacements curves for beams are shown in Figs. 4 to 13.

\section{CONCLUSIONS}

From the figures, the following can be concluded:

1- The suggesting formula in the two dimensional for numerical modeling gives results closer to the experimental work in cracking loads, ultimate loads, displacements and the longitudinal and lateral strains are smaller [5].

2- Modes of failures are the same for numerical and experimental results for both repaired and original beams.

3- The length of the plate in tension zone increases the flexural rigidity as well as the cracking and ultimate strength of repaired beams.

4- Gluing a plate in compression zone increases slightly the flexural rigidity as well as the cracking and ultimate strength of repaired beams. 


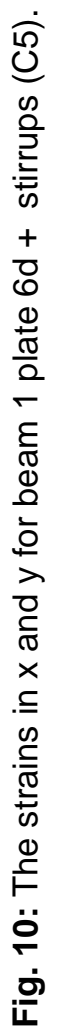




\section{REFERENCES}

[1] Abdel Rahman, M, and Usama, M.M. " Some parameters influencing the efficiency of some methods of repairing R.C.cracked beams.", INTERNATIONAL CONFERENCE ( FDCK 2 ) AUSTRIAN FEDERAL ECONOMIC CHAMBER VIENNA AUSTRIA 9-13 NOVEMBER 1992.

[2] Ajaya K. Gupta and Habiballah Akbar "Cracking in Reinforced Concrete ,Analysis", Journal of structural Engineering, Vol. 110, No. 8, August 1984, pp. 1735-1746.

[3] G. K. Schullerer. "A Numerical Investigation for the Analysis of Fiber Reinforced Composites with Respect to Macromechanical and Micromechanical Modeling". M.Sc. thesis, Innsbruck (Austria), Nov. (2000).

[4] K. J.Bathe. "Finite Element Procedures", 1996.

[5] Usama M., "Some parameters affecting the efficiency of repairing R.C. cracked beams", MS.c.thesis, Assiut (Egypt), Oct. (1991).

[6] W.F. Chen and H.Zhang. "Structural Plasticity"Springer, 1991.

\section{دراسة نظرية للكمرات الخرسانية المعالجة بلصث ألواح}

إن استخدام طرق التقوية و العـلاج للكمر ات الخرسـانية من الدر اسـات ذات الأهميـة

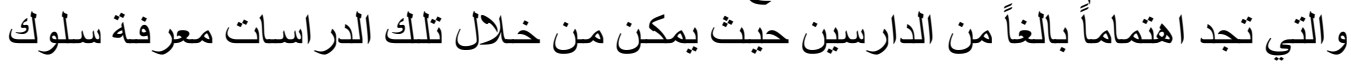

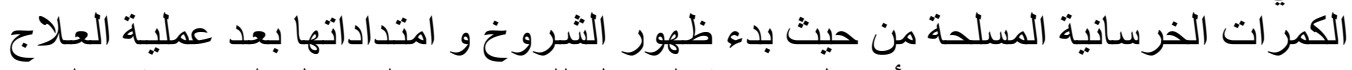

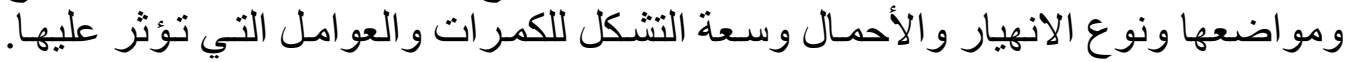

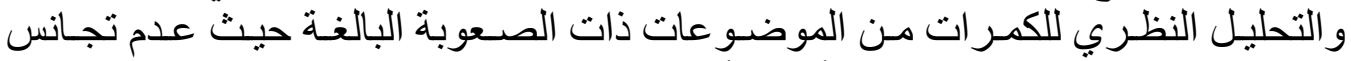

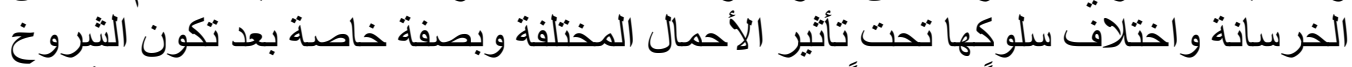

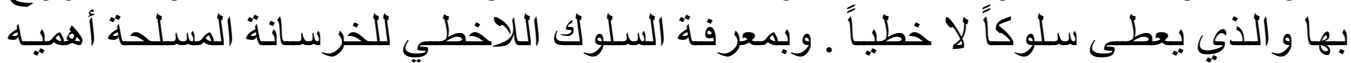

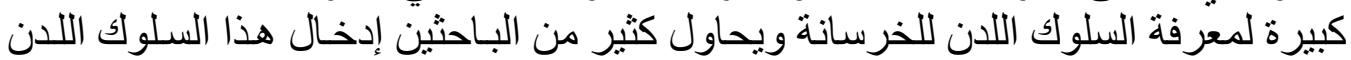

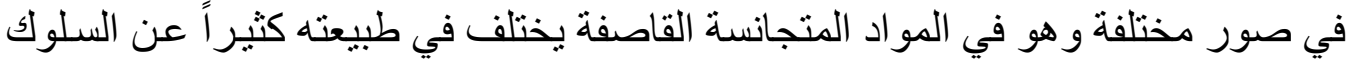

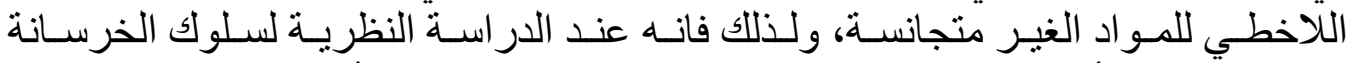

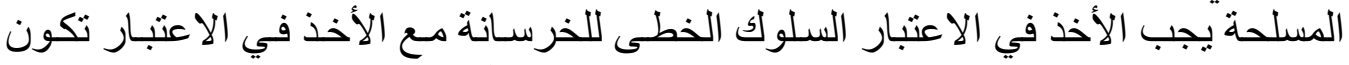

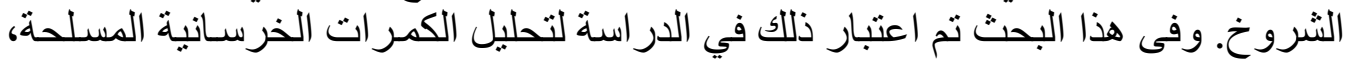

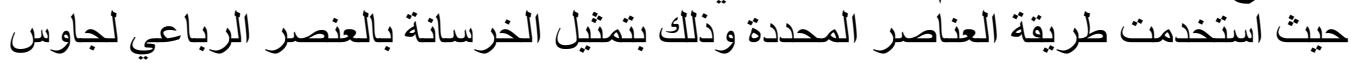

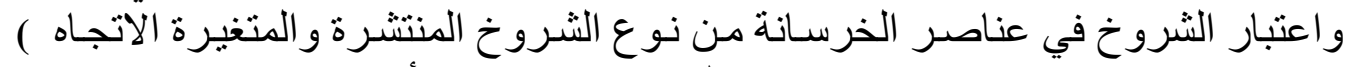

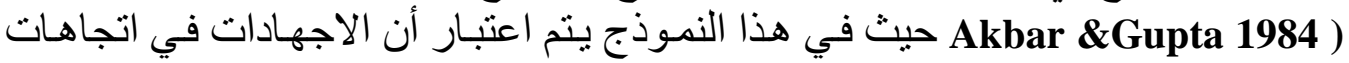

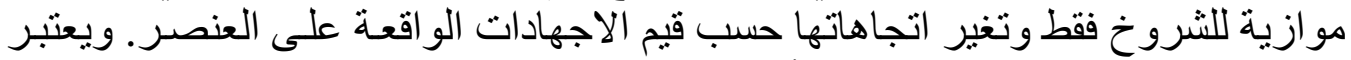

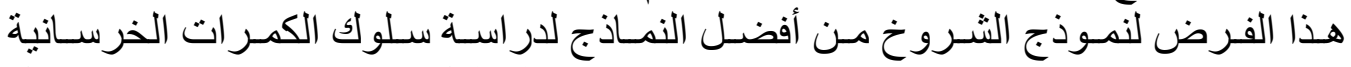

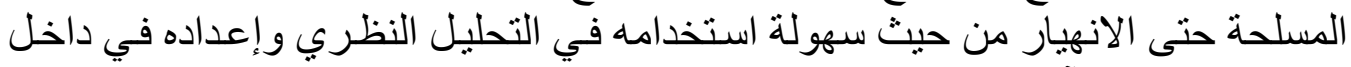
برنامج الحاسب الآلي. وقد تم في هذه الدر اسـة إيجـاد مصفوفات المتانـة باستخدام عامل 
( الكليـة للعنصـر الربـاعي الخرسـاني بعد (Shape Function)

الشكل

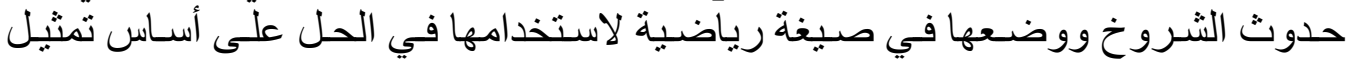

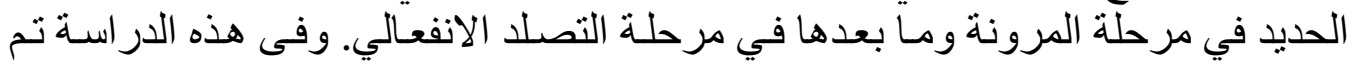

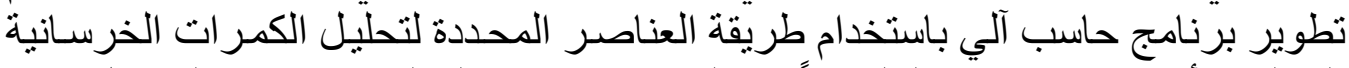

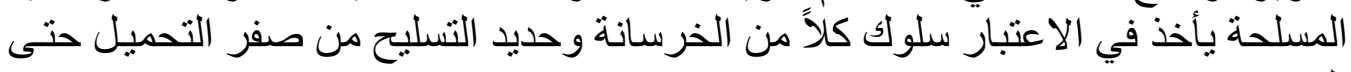

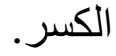

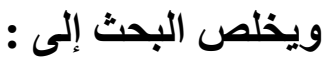

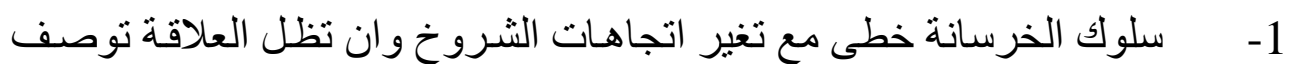

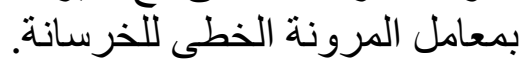

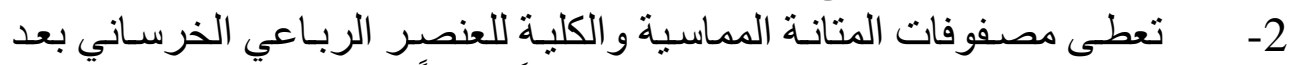

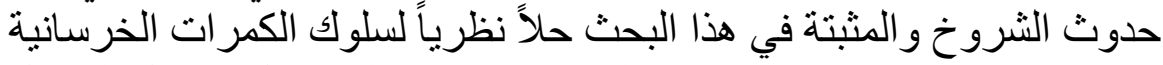

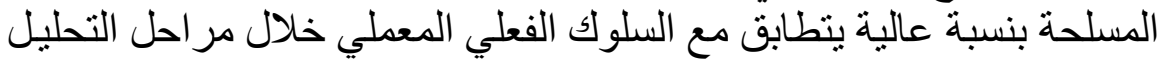

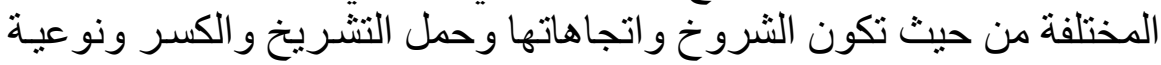

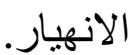

